\title{
What Exactly Is a Media Mentor?
}

RACHEL KEELER

A fter reading "Media Mentorship in Libraries Serving Youth," a white paper adopted by the Association for Library Service to Children board of directors, I had a lot to think about. The authors effectively outline why media mentorship is an ideal role for librarians, and I immediately started brainstorming, "What can I do today to be a media mentor to my community?"

I could start by having conversations with caregivers. At my library, we have an AWE Early Literacy Station computer, and I could encourage caregivers of younger children to try that, instead of our public computers. I could explain how it works and why it might be better suited for their child. This conversation would be a great transition into talking about digital media and joint engagement.

While I rarely see caregivers using the computer with their child, I have never made the suggestion that they do. However, I regularly remind caregivers that their children get more out storytimes when they participate.

Having these conversations with caregivers to help them make decisions regarding digital engagement will hopefully lead them to see me as a resource in this evolving library service.

Hoping to reach caregivers, I often place fliers for upcoming library programs in picturebooks. What if I worked with the other children's librarians in my system to create a handout with information about digital media? It's most important to convey that all media use should be interactive, with caregivers participating alongside their children.
While my branch library does not have tablets or a computer lab, I believe there is still much I can do to be a media mentor. To that end, I need to meet caregivers where they are-learning what kinds of digital media they are using with their kids. For example, if I offered a program focusing on how to best use phone apps with preschoolers, would caregivers be able to come with their own phones? I could easily help them connect to library WiFi and assist them in locating recommended apps. I could then demonstrate how to use these apps interactively with children, to encourage digital literacy and traditional literacy skills.

In the future, I plan to seek out ways to engage children, particularly those who might not have access to digital tools elsewhere, in enriching media experiences. Perhaps I could advocate for devices, or collaborate with another organization in my city. For now, I will begin by having conversations, sharing tips with caregivers, and educating myself further. $₫$.

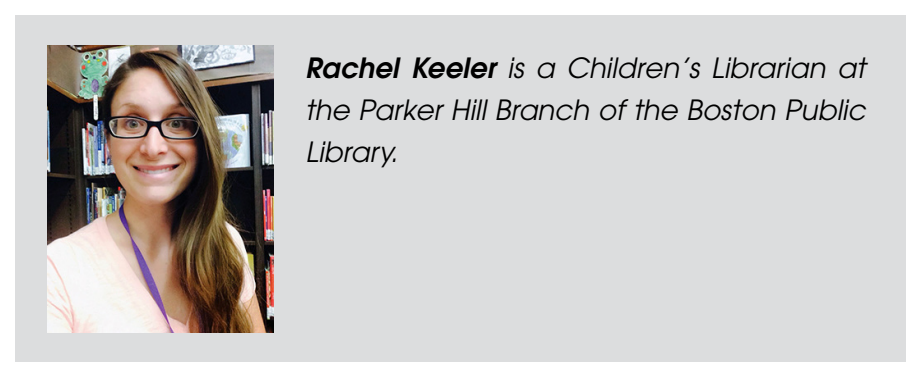

